\title{
HIGH BLOOD PRESSURE AND THE INCIDENCE OF NON-INSULIN DEPENDENT DIABETES MELLITUS: FINDINGS IN A 11.5 YEAR FOLLOW-UP STUDY IN THE NETHERIANDS
}

\author{
R.P. STOLK', I.P. VAN SPLUNDER, J.S.A.G. SCHOUTEN, J.C.M. WITTEMAN, \\ A. HOFMAN and D.E. GROBBEE \\ Department of Epidemiology and Biostatistics - Erasmus University Medical School - P.O. Box 1738 \\ 3000 DR - Rotterdam - The Netherlands.
}

Key words: Blood pressure - Diuretics - Heart rate - Obesity - Risk factors - Follow-up

To examine the contribution of cardiovascular risk factors to the development of non-insulin dependent diabetes mellitus, a prospective follow-up study was performed of a cohort, initially examined in a population survey on cardiovascular risk factors. The survey was conducted from 1975 to 1978 in the Netherlands among 5700 men and women aged 20 to 65 . In 1988 a questionnaire on the prevalence of chronic diseases, including diabetes mellitus, was sent to all living participants of the initial survey. The general practitioners of the persons who indicated to have diabetes mellitus were asked to confirm the diagnosis. Diabetes mellitus was defined as current use of oral hypoglycemic drugs or insulin. After exclusion of the prevalent cases at the initial survey, 65 incident confirmed cases remained. All others responding to the questionnaire served as controls.

The incidence of diabetes mellitus was associated with body mass index, use of diuretics, systolic and diastolic blood pressure. After adjustment for age and body mass index systolic and diastolic blood pressure were still associated with the incidence of non-insulin dependent diabetes mellitus in men; relative risks 1.28 (95\% confidence interval 1.06-1.54) and 1.40 (95\% CI 1.06-1.85) per $10 \mathrm{mmHg}$ respectively. For women, only the relative risk associated with the use of diuretics remained statistically significant $(2.26,95 \%$ CI $1.04-4.90)$. This probably reflects the risk of (treated) hypertension: adjusted for blood pressure, the relative risk lost statistical significance.

These findings suggest that elevated blood pressure is a risk for the development of non-insulin dependent diabetes mellitus (NIDDM). This supports the view that NIDDM and hypertension may have a similar origin.

\section{INTRODUCTION}

In several epidemiologic studies risk factors for the development of non-insulin dependent diabetes mellitus have been identified. Among these, the most important are age, obesity and glucose intolerance (2, $12,21,22)$. Studies on the association between other cardiovascular risk factors, e.g. hypertension, and the incidence of diabetes mellitus, however show conflicting results $(3,7,13)$. This is partly due to differences in definition of diabetes. Abnormal

\footnotetext{
Corresponding author.
}

glucose tolerance tests, fasting blood glucose levels above certain levels, health-questionnaires, hospital records, and the use of hypoglycemic medication are the most commonly used definitions. In addition, most studies have been cross-sectional, which preclused to investigate the time-sequence of the potential risk factor and the incidence of diabetes mellitus.

In the present study we used data obtained in a 11.5 year follow-up study of a large population in the Netherlands to prospectively assess the relation between cardiovascular risk factors and the incidence of diabetes mellitus. 


\section{SUBJECTS AND METHODS}

Between 1975 and 1978 a population survey was conducted in the Dutch town of Zoetermeer, among 5681 men and women aged 20 to 65 . The study was conducted among all the inhabitants of two suburbs (respons rate $78 \%$ ). The main objective of this population survey was to study determinants and prevalence of rheumatic diseases, chronic pulmonary diseases and cardiovascular diseases. Details of the study have been published previously (20). In 1988 a questionnaire on the presence of chronic diseases was sent to those between 20 and 65 years of age at the time of the initial survey. The questionnaire included two questions on diabetes mellitus: "Did you develop diabetes mellitus since the examination in 1975-1978?" and "Did you presently have diabetes mellitus?".

In the original survey blood pressure was measured on the left arm using a random zero sphygmomanometer. The mean of two readings in a sitting position was used in the analysis. Height and weight were measured without shoes and with indoor clothing. Body mass index was calculated as the ratio of weight to the square of height. Triceps skinfold was measured at the right and left arm. The mean of these two measurements was used in the analysis.

The questionnaire was sent to the 4968 subjects who were alive and whose current addresses were available in 1988. After one reminder, 3973 questionnaires were returned (response rate 80\%) and 133 participants answered positively to one of the diabetes questions. The general practitioners of the persons who indicated on the questionnaire that they had diabetes mellitus were contacted to confirm the diagnosis. Diabetes mellitus was defined as the current use of oral hypoglycemic drugs and/or insulin. Of each confirmed case, the general practitioner also provided the date of diagnosis. From all 133 persons, information was obtained from the general practitioners in 1989. At the initial survey in 1975-1978 the diagnosis of diabetes mellitus was made by a physician, using the same criteria. These prevalent cases were excluded from the analysis. The age of onset of all incident diabetic cases in this study was 36 years and over. The mean age of onset was 50.4 years for the 13 subjects using insulin; the insulin therapy started on average 3 years after the time of diagnosis. So we assumed that they all have non-insulin dependent diabetes. All others responding to the questionnaire who were not classified as having diabetes, and had complete data of the initial survey, served as controls $(n=3744)$. By comparing the baseline characteristics of the incident diabetic cases and the controls, it was possible to investigate the association between various cardiovascular risk factors and the incidence of diabetes mellitus.

After exclusion of the known diabetes patients in 1975-1978 $(\mathrm{n}=28)$ and the persons who did not had diabetes according to their general practitioner $(\mathrm{n}=$ 40), 65 incident cases of diabetes mellitus remained, 33 men and 32 women (incidence rate $1.5 / 1000$ person- years). The baseline characteristics at the survey in 1975-1978 of the persons who later developed diabetes mellitus and who did not develop diabetes mellitus, are given in Table 1.

For an additional analysis of the association between hypertension and the incidence of diabetes mellitus, the population was categorized according to the WHO-guidelines in normotensives (diastolic blood pressure $<90 \mathrm{mmHg}$ ), borderline hypertensives (diastolic $90-94 \mathrm{mmHg}$ ) and hypertensive (diastolic $\geq$ $95 \mathrm{mmHg}$ ) (1).

To investigate the association between cardiovascular risk factors and the incidence of diabetes mellitus, and to adjust for possible confounders, proportional hazard analysis was used. Analyses were performed both by entering determinants as continuous variables in the model and by using categorical variables based on quintiles of the distribution in the total population. For each cardiovascular risk factor the relative risk for diabetes mellitus and the 95\%-confidence interval was computed.

\section{RESULTS}

Age was significantly associated with the incidence of diabetes mellitus, with a relative risk of 1.05 per year for men $(95 \%$ confidence interval 1.02 1.09 ) and 1.10 for women (95\% CI 1.06-1.14). The results of the proportional hazard analysis of the cardiovascular risk factors assessed at baseline are given in Table 2. Body mass index, systolic and diastolic blood pressure were significantly associated with the incidence of diabetes mellitus in men and women, after adjustment for age. Heart rate in men, and skinfold thickness and use of diuretics in women also showed significant associations with the incidence of diabetes.

After adjustment for age and body mass index heart rate, systolic and diastolic blood pressure remained significantly associated with the incidence of diabetes mellitus in men. In women, only the relative risk associated with the use of diuretics remained statistically significant. By using categorical variables the risk of diabetes mellitus appeared to rise gradually with increasing blood pressure level and body mass index. By contrast, for heart rate in men the relative risk of diabetes was raised in particular in the highest quintile. After adjustment for age, body mass index and systolic blood pressure, the association of heart rate and diuretics with the incidence of diabetes were no longer statistically significant. In men the relative risk was $1.25(95 \% \mathrm{CI} 0.97-1.62)$ for heart rate and 1.62 $(95 \%$ CI 0.48-5.44) for diuretics. In women these relative risks were $1.05(95 \% \mathrm{CI} 0.80-1.38)$ and 2.18 (95\% CI 1.00-4.78) respectively. Similar results were obtained after adjustment for diastolic blood pressure.

To exclude the effect of anti-hypertensive medication on the association of blood pressure and the development of diabetes mellitus, those subjects 
TABLE 1. - Baseline characteristics of participants in the initial survey, according to subsequent development of diabetes mellitus.

\begin{tabular}{|c|c|c|c|c|}
\hline & \multicolumn{2}{|c|}{ Men } & \multicolumn{2}{|c|}{ Women } \\
\hline & $\mathrm{DM}+*$ & DM- & DM+ & DM- \\
\hline $\begin{array}{l}\text { Number } \\
\text { Age (years) }\end{array}$ & $47.6^{33}(10.5)$ & $41.7^{1747}(11.0)$ & $51.9^{32}(8.1)$ & 41.597 \\
\hline $\begin{array}{l}\text { Body mass index }\left(\mathrm{kg} / \mathrm{m}^{2}\right) \\
\text { Skinfold thickness }(\mathrm{mm})+\end{array}$ & $\begin{array}{l}26.6 \quad(3.0) \\
11.2 \quad(4.4)\end{array}$ & $\begin{array}{l}24.2 \quad(2.9) \\
10.1 \quad(4.4)\end{array}$ & $\begin{array}{ll}28.6 & (4.5) \\
25.0 & (6.7)\end{array}$ & $\begin{array}{ll}23.8 & (3.3) \\
19.0 & (6.6)\end{array}$ \\
\hline $\begin{array}{l}\text { Heart rate (beats/min) } \\
\text { Systolic blood pressure ( } \mathrm{mmHg} \text { ) } \\
\text { Dyastolic blood pressure }(\mathrm{mmHg}) \\
\text { Cholesterol (mmol/l) } \\
\text { Hypertension } \dagger \\
\text { Use of diuretics }\end{array}$ & $\begin{array}{cc}81.6 & (14.0) \\
144.6 & (18.7) \\
87.1 & (11.5) \\
6.0 & (1.2) \\
36.4 \% & \\
9.1 \% & \end{array}$ & $\begin{array}{cc}75.5 & (12.8) \\
132.3 & (17.0) \\
79.3 & (11.8) \\
5.8 & (1.1) \\
15.3 \% & \\
3.2 \% & \end{array}$ & $\begin{array}{cc}79.3 & (12.8) \\
144.3 & (25.1) \\
88.1 & (15.5) \\
6.5 & (1.2) \\
56.2 \% & \\
37.5 \% & \end{array}$ & $\begin{array}{cc}78.4 & (12.9) \\
127.4 & (18.4) \\
78.1 & (12.0) \\
5.7 & (1.1) \\
17.6 \% & \\
8.4 \% & \end{array}$ \\
\hline $\begin{array}{l}\text { Coffee use (cups/day) } \\
\text { Current smoking }\end{array}$ & $\begin{array}{l}4.7 \\
53.3 \%\end{array}(2.1)$ & $\underset{58.9 \%}{5.3}(2.4)$ & $\begin{array}{l}4.2 \\
54.5 \%\end{array}(1.9)$ & $\begin{array}{l}4.5 \\
61.9 \%\end{array}$ \\
\hline
\end{tabular}

Values are means with standard deviation in parentheses.

* $\mathrm{DM}+$ are persons who developed diabetes mellitus during the follow-up period, DM- persons who did not develop diabetes mellitus during the follow-up period.

+ Measured in $73 \%$ of men and women.

$\dagger$ Systolic blooc pressure $\geq 160 \mathrm{mmHg}$ or diastolic blood pressure $\geq 95 \mathrm{mmHg}$ or using anti-hypertensive medication.

TABLE 2. - Relative risk of diabetes mellitus for several cardiovascular risk factors.

\begin{tabular}{|c|c|c|c|c|}
\hline & \multicolumn{2}{|c|}{ Adjusted for age } & \multicolumn{2}{|c|}{ Adjusted for age and BMI } \\
\hline & Men & Women & Men & Women \\
\hline Body mass index $\left(5 \mathrm{~kg} / \mathrm{m}^{2}\right)$ & $\begin{array}{c}2.78 \\
(1.78-4.35)\end{array}$ & $\begin{array}{c}3.44 \\
(2.35-5.02)\end{array}$ & - & - \\
\hline Skinfold thickness $(\mathrm{mm})^{*}$ & $\begin{array}{c}1.05 \\
(0.97-1.13)\end{array}$ & $\begin{array}{c}1.09 \\
(1.04-1.16)\end{array}$ & $\begin{array}{c}0.94 \\
(0.86-1.03)\end{array}$ & $\begin{array}{c}1.03 \\
(0.96-1.10)\end{array}$ \\
\hline Heart rate $(10$ beats $/ \mathrm{min})$ & $\begin{array}{c}1.37 \\
(1.08-1.73)\end{array}$ & $\begin{array}{c}1.08 \\
(0.84-1.40)\end{array}$ & $\begin{array}{c}1.34 \\
(1.05-1.71)\end{array}$ & $\begin{array}{c}1.07 \\
(0.82-1.40)\end{array}$ \\
\hline Systolic blood pressure $(10 \mathrm{mmHg})$ & $\begin{array}{c}1.34 \\
(1.12-1.60)\end{array}$ & $\begin{array}{c}1.24 \\
(1.06-1.46)\end{array}$ & $\begin{array}{c}1.28 \\
(1.06-1.54)\end{array}$ & $\begin{array}{c}1.08 \\
(0.91-1.29)\end{array}$ \\
\hline Diastolic blood pressure $(10 \mathrm{mmHg})$ & $\begin{array}{c}1.51 \\
(1.17-1.95)\end{array}$ & $\begin{array}{c}1.44 \\
(1.13-1.85)\end{array}$ & $\begin{array}{c}1.40 \\
(1.06-1.85)\end{array}$ & $\begin{array}{c}1.13 \\
(0.87-1.47)\end{array}$ \\
\hline Cholesterol (mmol/l) & $\begin{array}{c}1.00 \\
(0.73-1.38)\end{array}$ & $\begin{array}{c}1.28 \\
(0.94-1.75)\end{array}$ & $\begin{array}{c}0.93 \\
(0.68-1.28)\end{array}$ & $\begin{array}{c}1.23 \\
(0.90-1.67)\end{array}$ \\
\hline Hypertensiont & $\begin{array}{c}2.35 \\
(1.12-4.96)\end{array}$ & $\begin{array}{c}3.17 \\
(1.49-6.72)\end{array}$ & $\begin{array}{c}1.84 \\
(0.86-3.92)\end{array}$ & $\begin{array}{c}1.98 \\
(0.92-4.26)\end{array}$ \\
\hline Use of diuretics & $\begin{array}{c}2.02 \\
(0.60-6.78)\end{array}$ & $\begin{array}{c}3.46 \\
(1.64-7.31)\end{array}$ & $\begin{array}{c}1.82 \\
(0.54-6.11)\end{array}$ & $\begin{array}{c}2.26 \\
(1.04-4.90)\end{array}$ \\
\hline Coffee use (cups/day) & $\begin{array}{c}0.90 \\
(0.76-1.06)\end{array}$ & $\begin{array}{c}0.94 \\
(0.78-1.13)\end{array}$ & $\begin{array}{c}0.88 \\
(0.74-1.04)\end{array}$ & $\begin{array}{c}0.87 \\
(0.72-1.05)\end{array}$ \\
\hline Current smoking & $\begin{array}{c}1.05 \\
(0.73-1.50)\end{array}$ & $\begin{array}{c}1.10 \\
(0.72-1.67)\end{array}$ & $\begin{array}{c}1.05 \\
(0.73-1.50)\end{array}$ & $\begin{array}{c}1.11 \\
(0.73-1.68)\end{array}$ \\
\hline
\end{tabular}

Values are relative risks, with $95 \%$ confidence interval in parentheses.

* Measured in $73 \%$ of men and women.

+ Systolic blood pressure $\geq 160 \mathrm{mmHg}$ or diastolic blood pressure $\geq 95 \mathrm{mmHg}$ or using anti-hypertensive medication. 
using anti-hypertensive medication were excluded from the analysis. The results were essentially the same as in the groups as a whole: adjusted for age, the relative risks for systolic blood pressure were 1.38 per $10 \mathrm{mmHg}$ (95\% confidence interval 1.15-1.66) in men, and 1.22 (95\% CI 1.01-1.48) in women respectively. When the analysis was restricted to the subjects with normal blood pressure (systolic blood pressure $\leq 160$ $\mathrm{mmHg}$ ) the relative risks for systolic blood pressure were 1.41 per $10 \mathrm{mmHg}(95 \% \mathrm{Cl} 1.06-1.89)$ in men and $1.16(95 \% \mathrm{CI} 0.87-1.55)$ in women, adjusted for age.

In additional analysis of the risk related to elevated blood pressure, the population was categorized into three groups: normotensives, borderline hypertensives, and hypertensives. The findings in this analysis are shown in Figure 1, adjusted for age. In men and women the relative risk of diabetes mellitus increased with each blood pressure category. In both men and women this trend was statistically significant.



For the definition of the different hypertensive categories, see text. Numbers indicate the proportion of incident diabetic cases in each category.

Test for trend: ${ }^{*} \mathrm{p}<0.05,{ }^{* *} \mathrm{p}<0.01$.

Figure 1. - Relative risk of diabetes mellitus in normotensive subjects and categories of hypertension.

\section{DISCUSSION}

The results of our study show that age, body mass index, systolic and diastolic blood pressure is associated with the incidence of diabetes mellitus during a follow-up period of 11.5 years. In men there is also an association with heart rate, whereas in women skinfold thickness and the use of diuretics are significantly associated with the incidence of diabetes mellitus. After adjustment for age and body mass index, in men heart rate, systolic and diastolic blood pressure and in women the use of diuretics remain significantly associated with the incidence of diabetes mellitus. When the effect of anti-hypertensive medication (especially thiazide diuretics) is excluded, the association of blood pressure and diabetes mellitus remains statistically significant. However, before we can accept these findings, some issues need to be discussed.

Diagnosis of diabetes mellitus in our study was based on participant response to the questionnaire with subsequent confirmation by general practitioners. By using current hypoglycemic medication as criterion for the diagnosis of diabetes mellitus, false-positive misclassification is not likely to occur. It is known that the rate of undiagnosed diabetes mellitus is about the same as the rate of diagnosed diabetes (11). So the use of these strict criteria may have led to an underestimation of the incidence of diabetes. However, when the number of incident cases is small compared to the whole study population, false-positive misclassification is more important then false-negative misclassification (4). This will, if anything, reduce the magnitude of the risk estimates.

Several epidemiologic studies have shown that age is an important risk factor for the development of non-insulin dependent diabetes mellitus. Also, overweight and body fat distribution are well documented risk factors (2). In our study we were able to confirm that age and overweight are significantly associated with the development of diabetes mellitus. Triceps skinfold thickness, the only measure of body fat obtained in the initial survey, is not appropriate to assess body fat distribution, and has found in other studies to have only a weak association with the incidence of non-insulin dependent diabetes mellitus (8). Unfortunately, no blood glucose levels were measured at baseline, so no information could be obtained about the third important risk factor for the development of non-insulin dependent diabetes mellitus, glucose intolerance (13). Because the mean time between the initial survey and the diagnosis of diabetes mellitus was 7.3 year, it is not likely that a substantial proportion of the 'incident' diabetic cases actually had diabetes mellitus during the initial survey.

Of the cardiovascular risk factors studied, serum cholesterol and smoking showed no association with the development of non-insulin dependent diabetes mellitus. However, the mean cholesterol levels was slightly higher in persons who later developed diabetes mellitus $(p=0.28)$, so the possibility of a small risk associated with serum cholesterol can not completely ruled out. Coffee consumption, although not a cardiovascular risk factor (9), has been suggested to be a risk factor for the development of insulin dependent diabetes mellitus (19). We found no association between coffee consumption and the incidence of non-insulin dependent diabetes mellitus.

The risk associated with the use of diuretics was remarkably high in women, but the risk associated with raised blood pressure, both systolic and diastolic, was lower than in men. After controlling in the 
analysis for blood pressure the risk associated with diuretic use moved close to one. Although the diabetogenic effects of diuretics, in particular thiazides, have been reported by several authors (14, 16), our findings may indicate that the risk associated with the use of diuretics mainly reflects the risk of (treated) hypertension. In accordance with this, when blood pressure was included in the analysis, diuretic use lost its relation with the development of diabetes mellitus. When the subjects using antihypertensive medication were excluded from the analysis, the association between blood pressure and the incidence of diabetes mellitus remained, also in the normopressure range.

It should be stressed that, because prevalent cases of diabetes were excluded from this prospective study, blood pressure was recorded before diabetes mellitus developed. In addition, the results given in Figure 1 suggest a dose-response relation between blood pressure and the incidence of non-insulin dependent diabetes mellitus. Together with the results from the analysis of the anti-hypertensive medication, this supports the view that NIDDM and hypertension may have a similar origin $(10,17)$. According to several authors this common cause is a raised insulin resistance $(5,6,15,18)$. This would imply that elevated blood pressure, whether treated or not, at the survey in 1975-1978 was a first sign of hyperinsulinism in those subjects who later developed diabetes mellitus.

In summary, from our study it appears that, in addition to age and obesity, high blood pressure is a risk factor for non-insulin dependent diabetes mellitus.

\section{Acknowledgements}

We are indebted to the participants of the EPOZ study for their willingness to continue their cooperation, and to the general practitioners of Zoetermeer for providing confirmation of the diagnosis of their diabetic patients.

\section{REFERENCES}

1. Anonymous (1989): Guidelines for the management of mild hypertension memorandum from a $\mathrm{WHO} /$ ISH meeting - J. Hypertension 7: 689-693.

2. Barrett-Connor E. (1989): Epidemiology, obesity, and non-insulin-dependent diabetes mellitus Epidemiol. Rev. 11: 172-181.

3. Butler W.J., Ostrander L.D., Carman W.J. and Lamphiear D.E. (1982): Diabetes mellitus in Tecumseh, Michigan. Prevalence, incidence, and associated conditions - Am. J. Epidemiol. 116: 971980.

4. Copeland K.T., Checkoway H., McMichael A.J. and Holbrook R.H. (1977): Bias due to misclassification in the estimation of relative risk - Am. J. Epidemiol. 105: 488-495.
5. De Fronzo R.A. and Ferranini E. (1991): Insuline resistance: a multifaced syndrome responsible for NIDDM, hypertension dyslipidemia, and atherosclerotic cardiovascular disease - Diabetes Care 14: 173-194.

6. Ferrari P. and Weidman P. (1990): Insulin, insulin sensitivity and hypertension - J. Hypertension $8: 491$ 500.

7. Feskens E.J.M. and Kromhout D. (1989): Cardiovascular risk factors and the 25-year incidence of diabetes mellitus in middle-aged men. The Zutphen Study - Am. J. Epidemiol. 130: 1101-1108.

8. Feskens E.J.M. and Kromhout D. (1989): Effects of body fat and its development over a ten-year period on glucose tolerance in euglycaemic men: The Zutphen Study - Int. J. Epidemiol. 18: 368-373.

9. Grobbee D.E., Rimm E.B., Giovannucci E., Colditz G., Stampfer M. and Willett W. (1990): Coffee, caffeine, and cardiovascular disease in men - N. Eng. J. Med. 323: 1026-1032.

10. Haffner S.M., Stern M.P., Hazuda H.P., Mitcheil B.D. and Patterson J.K. (1990): Cardiovascular risk factors in confirmed prediabetic individuals. Does the clock for coronary heart disease start thicking before the onset of clinical diabetes? - JAMA 263: 2893-2898.

11. Harris M.I., Hadden W.C., Knowler W.C. and Bennett P.H. (1987): Prevalence of diabetes and impaired glucose tolerance and plasma glucose levels in U.S. population aged 20-74 years - Diabetes 36: 523-534.

12. Jarrett R.J. (1989): Epidemiology and public health aspects of non-insulin-dependent diabetes mellitus Epidemiol. Rev. 11: 151-171.

13. McPhillips J.B., Barrett-Connor E. and Wingard D.L. (1990): Cardiovascular disease risk factors prior to the diagnosis of impaired glucose tolerance and noninsulin dependent diabetes mellitus in a community of older adults - Am. J. Epidemiol. 131: 443-453.

14. Murphy M.B., Lewis P.J., Kohner E., Schumer B. and Dollery C.T. (1982): Glucose intolerance in hypertensive patients treated with diuretics. A fourteen-year follow-up - Lancet ii: 1293-1295.

15. Reaven G.M. (1988): Role of insulin resistance in human disease. Banting lecture - Diabetes 37: 15951607.

16. Skarfors E.T., Lithell H.O., Selinus I. and Aberg H. (1989): Do anti-hypertensive drugs precipitate diabetes in predisposed men? - Br. Med. J. 298:11471152.

17. Smith U. (1990): Insulin resistance. A major hazard for cardiovascular disease? (editorial) - J. Intern. Med. 227: 219-220. 
18. Swislocki A. (1990): Insulin resistance and hypertension - Am. J. Med. Sci. 300: 104-115.

19. Toumilehto J., Tuomilehto-Wolf E., Virtala E. and La Porte R. (1990): Coffee consumption as trigger for insulin dependent diabetes mellitus in childhood Br. Med. J. 300: 642-643.

20. Valkenburg H.A., Hofman A., Klein F. and Groustra F.N. (1980): An epidemiologic study of cardiovascular risk indicators (EPOZ). I. Blood pressure, serum cholesterol Quetelet index and smoking habits in an open population aged 5 years and over (abstract in English) - Ned. Tijdschr Geneesk 124: 183-189.

21. Wilson P.W.F., Kannel W.B. and Anderson K.M. (1985): Lipids, glucose intolerance and vascular disease: The Framingham Heart Study - Monogr Atheroscler. 13: 1-11.

22. World Health Organization (1985): Technical report series 727 . Diabetes Mellitus, Geneva. 